\title{
Effect of seepage-stress coupling on stress and deformation of cutoff wall
}

\author{
${ }^{a} X . X . H E$, R.J. WANG \& F. YAN, ${ }^{b} Y . X . F A N$ \\ ${ }^{a} X i ' a n$ University of Technology, Xi'an, Shaanxi, China \\ ${ }^{b}$ Water Conservation Bureau of Tongliao City, the Inner Mongolia Autonomous Region, China
}

\begin{abstract}
KEYWORD: Gate dam; Concrete cutoff wall; Seepage-stress coupling; Stress and deformatio ABSTRACT: In order to study the stress and deformation characteristics of concrete cutoff wall in deep overburden foundation and the influence of seepage-stress coupling on the cutoff wall, combined with a practical project, using Abaqus finite element calculation software, the whole threedimensional finite element model of the dam is built to calculate. The results show that the stress and deformation are concentrated in the top of the cutoff wall, and show the tendency of decreasing with the depth increased. By comparing the results of stress and deformation of concrete cutoff wall with consider or not consider seepage-stress coupling, founded that when consider the coupling effect, the displacement and the principal stress of cutoff wall varied at some degree. Therefore, ignoring the seepage-stress coupling can lead to the result of stress and deformation of the concrete cutoff wall is small.
\end{abstract}

\section{INTRODUCTION}

Gate dam is a low head hydraulic structure, which has the function of stopped the flood, flood discharge and drainage, or to adjust the flow according to the downstream water need (Lin 2009), it has been widely used in hydraulic engineering. With the development of water resources, there are many dam engineering on the deep overburden at present (Yang 2004), and quite a few are being built or designed(Zhou \& Chen 2004). Due to the distribution of the covering layer is poor, the engineering often meets the foundation bearing capacity is low, the uneven settlement is big, the seepage is not stable and so on. However, as the most widely used foundation seepage prevention structure in the deep overburden foundation (Yang 2003), the concrete cutoff wall plays an important role in the normal operation of the gate dam project (Zheng 2013).

Guo Xuemang and others (Guo 2005) using nonlinear finite element analysis of a plain reservoir that the wall stress will gradually increase with the increase of the water level, especially in the middle and upper part of the wall. Liu Na (Liu 2007) from the top of the cutoff wall will be the stress concentration and the maximum vertical stress of the cutoff wall will not appear at the top of the cutoff wall of these two phenomena, analysis of the distribution of the stress and deformation of the diaphragm wall.

The soil permeability of deep overburden layer is strong, there is a certain pore water pressure in the soil, which will inevitably affect the stress and deformation of the concrete cutoff wall, which can not be ignored (Zhou 2013), previous studies always focus on the stress and deformation under single stress field, and the effect of seepage field and stress field on the interaction of seepage field and stress field is seldom considered (Gao 2012). In view of the above problems, this paper intends to study the influence of seepage-stress coupling on stress and deformation of concrete cutoff wall in deep overburden foundation, so as to provide reference for practical engineering to solve the key technical problems such as seepage control and stress deformation control.

\section{THE BASIC PRINCIPLE OF SEEPAGE-STRESS COUPLING}

In the geotechnical engineering field, seepage-stress coupling study refers to the coupling between seepage and stress field, which is the result of joint development between geotechnical mechanics and seepage mechanics in the engineering field. 
(1)The influence of seepage field on stress field (Chai \& Li 2002)

From the principles of the finite element method, the influence of seepage field on stress field is the increment of unit nodal force caused by seepage represented by node pore water pressure. Based on the hydraulics principle, permeate volume strength is proportional to hydraulic gradient, at any point water head in the unit can be indicated using unit node water head $\{H\}^{e}$, similarly unit nodes water head of $t$ and $t+\Delta t$ times are indicated by $\{H\}_{t}^{e} 、\{H\}_{t+\Delta t}^{e}$ respectively. So it can obtain change values $\left(\Delta f_{x}, \Delta f_{y}, \Delta f_{z}\right)$ of unit volume force in the $x, y, z$ three directions at the $t$ and $t+\Delta t$ times.

$$
\left\{\begin{array}{l}
\Delta f_{x}=-\gamma_{w}\left[\frac{\partial N_{1}}{\partial x}, \frac{\partial N_{2}}{\partial x}, \frac{\partial N_{3}}{\partial x}, \mathrm{~L}, \frac{\partial N_{8}}{\partial x}\right]\left(\{H\}_{t+\Delta t}^{e}-\{H\}_{t}^{e}\right) \\
\Delta f_{y}=-\gamma_{w}\left[\frac{\partial N_{1}}{\partial y}, \frac{\partial N_{2}}{\partial y}, \frac{\partial N_{3}}{\partial y}, \mathrm{~L}, \frac{\partial N_{8}}{\partial y}\right]\left(\{H\}_{t+\Delta t}^{e}-\{H\}_{t}^{e}\right)(1) \\
\Delta f_{z}=-\gamma_{w}\left[\frac{\partial N_{1}}{\partial z}, \frac{\partial N_{2}}{\partial z}, \frac{\partial N_{3}}{\partial z}, \mathrm{~L}, \frac{\partial N_{8}}{\partial z}\right]\left(\{H\}_{t+\Delta t}^{e}-\{H\}_{t}^{e}\right)
\end{array}\right.
$$

Where $\gamma_{w}=$ Fluid weight; $[N]=$ shape function matrixes; $[N]=\left[N_{1}, N_{2}, N_{3}, \cdots N_{8}\right]$.

(2)The influence of stress field on seepage field (Chai \& Li 2002)

Soil medium can produce deformation due to the effect of stress, which makes the porosity or void ratio of soil medium changes, and further affects its permeability coefficient. The relationship expression between the void ratio and permeability coefficient in sandy soil is shown below.

$$
k=C_{2} D_{10}^{2.32} C_{u}^{0.6} \frac{e^{3}}{1+e}=C_{2} D_{10}^{2.32} C_{u}^{0.6} \frac{n^{3}}{(1-n)^{2}}
$$

Where $k=$ permeability coefficient when the void ratio is $e ; D_{10}=10 \%$ effective diameter; $C_{u}=$ non-uniformity coefficient; $n=$ porosity; and $e=$ void ratio.

Soil porosity and volumetric strain of soil has a direct relationship. Assume that soil particles and the fluid are incompressible, by the constitutive relation of soil, volumetric strain can be indicated by stress $\sigma_{\mathrm{ij}}$. Therefore, the permeability coefficient is expressed by the stress function eventually, in other words, it is the influence of the stress field on seepage field.

$$
k=k\left(\sigma_{i j}\right)
$$

\section{PROJECT PROFILE}

The water retaining structure of hydropower use the gate dam,and rank isI.Gate dam is setted 5 open type sluice and used radial gate. Each sluice lock chamber $47 \mathrm{~m}$ long, $13 \mathrm{~m}$ wide, sluice bottom thickness is $6 \mathrm{~m}$, abutment pier thickness is $3.5 \mathrm{~m}$, and gate pier's is $7 \mathrm{~m}$. The top elevation of lock chamber is $1653 \mathrm{~m}$, and the maximum height of the gate dam is $38 \mathrm{~m}$. Using energy dissipation of hydraulic jump as tailrace energy dissipation, and the length of the stilling basin is $84 \mathrm{~m}$. At the end of the stilling basin set a open caisson with $15 \mathrm{~m}$ wide, $23 \mathrm{~m}$ deep as protection. In the upstream side of the lock chamber pave the anti-scour blanket with length of $30 \mathrm{~m}$. Paving the blanket on the upstream floor and setting up fully enclosed concrete cutoff wall under the blanket as the gate dam foundation anti-seepage control. And the thickness of the concrete cutoff wall is $0.8 \mathrm{~m}$, corresponding material is $\mathrm{C} 20$ plastic concrete. Meanwhile, using the curtain grouting as seepage control around the dam on the both sides of the joint. The maximum covering layers thickness is about $47.75 \mathrm{~m}$, and it can be divided intoI IV layers. From top to bottom in turn as follows:Ilayer, rubble and gravel stratum, thickness is about 10 15 m; II layer, solitary stone gravel layer, thickness is about $8 \sim 12 \mathrm{~m}$; III layer, sand loam crushed gravel layer, thickness is about 9 11 m; IV layer, boulders and gravel, thickness is about 10 20 m. 


\section{COMPUTATIONAL MODEL}

\section{Finite element model and mesh generation}

Finite element analysis using Abaqus finite element calculation software, the calculation range is the whole gate dam and a certain range of foundation. The element of the gate dam and the cutoff wall adopts the eight surface body elements, and the contact element adopts the Goodman non thickness contact element. The finite element mesh is shown in Figure 1. In consideration of seepage-stress coupling effect of overburden layer, element type selected seepage-stress coupling pore pressure elements.

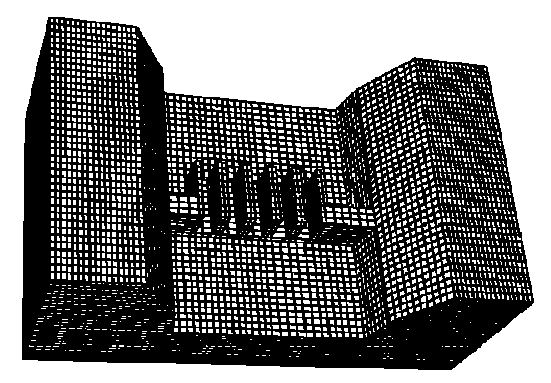

Figure 1. 3D finite element meshes of sluice

\section{Calculation condition}

Condition 1: normal water level condition, the head-water level is $1646.00 \mathrm{~m}$; the downstream water level is $1624.80 \mathrm{~m}$.

Condition 2: design flood level condition, the head-water level is $1648.15 \mathrm{~m}$; the downstream water level is $1643.00 \mathrm{~m}$.

Condition 3: check flood level condition, the head-water level is $1651.16 \mathrm{~m}$; the downstream water level is $1645.20 \mathrm{~m}$.

\section{Calculation parameters}

The seepage coefficient and initial void ratio of the dam concrete material and the dam foundation are shown in Table 1. The non linear elastic Duncan-Chang model was used for the cutoff wall and the overburden layer, material parameters are shown in Table 2; The linear elastic model is adopted for the gate dam concrete and the bedrock, the density of the bedrock is $2.4 \mathrm{~g} / \mathrm{cm}^{3}$, the elastic modulus is $8 \mathrm{GPa}$, the Poisson's ratio is 0.3 , the density of the dam concrete is $2.0 \mathrm{~g} / \mathrm{cm}^{3}$, the elastic modulus is $350 \mathrm{MPa}$, the Poisson's ratio is 0.167 .

The contact surface between the dam foundation and the concrete cutoff wall adopts the Goodman element, internal friction angle of $11.5^{\circ}$, the cohesive force is $0 \mathrm{kPa}$, the normal stiffness coefficient of extrusion state is $10^{6} \mathrm{MPa} / \mathrm{m}$, the normal stiffness coefficient of tension state is $10^{4} \mathrm{MPa} / \mathrm{m}$.

Table 1. Seepage calculation parameters.

\begin{tabular}{lll}
\hline \multirow{2}{*}{ Material } & \multicolumn{2}{l}{ Permeability coefficient K } \\
\cline { 2 - 2 } & $\mathrm{m} / \mathrm{s}$ & Initial void ratio \\
\hline Rubble and gravel layer & $2 \times 10^{-1}$ & 0.4 \\
Solitary stone gravel layer & $3.5 \times 10^{-2}$ & 0.6 \\
Broken gravel layer & $1.9 \times 10^{-3}$ & 0.45 \\
Boulders and gravel layer & $4 \times 10^{-2}$ & 0.6 \\
Bedrock & $1 \times 10^{-6}$ & 0.5 \\
Concrete & $1 \times 10^{-9}$ & 1.0 \\
\hline
\end{tabular}


Table 2. Impervious wall and layer soil material E-B model parameters

\begin{tabular}{|c|c|c|c|c|c|c|c|c|c|}
\hline \multirow{2}{*}{ Material } & \multirow{2}{*}{$K$} & \multirow{2}{*}{$n$} & \multirow{2}{*}{$R_{f}$} & \multirow{2}{*}{$K_{u r}$} & \multirow{2}{*}{$K_{b}$} & \multirow[b]{2}{*}{$m$} & $\gamma$ & $c$ & $\varphi$ \\
\hline & & & & & & & $\mathrm{g} / \mathrm{cm}^{3}$ & $\mathrm{kPa}$ & o \\
\hline Cutoff wall concrete & 3112 & 0.08 & 0.82 & 3734 & 2210 & -0.486 & 2.4 & 200 & 28.7 \\
\hline Rubble and gravel & 1594.7 & 0.32 & 0.74 & 2551.5 & 545.9 & 0.26 & 2.3 & 0 & 30 \\
\hline Solitary stone gravel & 898 & 0.38 & 0.81 & 1436.8 & 393 & 0.06 & 1.88 & 0 & 18 \\
\hline Broken gravel layer & 1594.7 & 0.32 & 0.74 & 2551.5 & 545.9 & 0.26 & 2.3 & 0 & 30 \\
\hline Boulders and gravel & 1250 & 0.55 & 0.75 & 2000 & 1000 & 0.3 & 2.0 & 0 & 20 \\
\hline
\end{tabular}

* $K$ is initial tangent modulus cardinality of elasticity, $n$ is index of initial tangent modulus of elasticity, $R_{f}$ is damage ratio, $K_{u r}$ is the elastic modulus cardinality of unloading and loading, $K_{b}$ is cardinality of initial bulk modulus, $m$ is index of initial bulk modulus, $\gamma$ is bulk density, $c$ is cohesion, $\varphi$ is internal friction angle, $E$ is elastic modulus, $v$ is Poisson's ratio.

\section{Load and boundary conditions}

(1) Load

The main load is: the upper and lower reaches of the water pressure; uplift pressure; foundation and structural weight.

The construction of the dam and the storage of the reservoir are simulated by the method of staged loading, gravity is applied in the form of physical strength. When the seepage-stress coupling is not considered, the water pressure and uplift pressure of the dam and the cutoff wall are in the form of the surface force acting on the dam body and the cutoff wall; when the seepage-stress coupling is considered, the water pressure and uplift pressure of the cutoff wall are generated automatically by applying the pore pressure boundary condition, and the water pressure and uplift pressure of the dam are in the form of the surface force.

(2) Boundary conditions

Plus three directions fixed constraint at the bottom of the model, adding chain link in the side of the model. Pore water pressure boundary conditions are imposed on the cutoff wall when the seepagestress coupling is considered.

\section{CALCULATION RESULTS AND ANALYSIS}

The results of stress calculation take the tensile stress as the positive, and the compressive stress is negative; the results of horizontal displacement take the direction of downstream as the positive, and the upstream is negative; the vertical displacement take the direction of upward as the positive, and the downward is negative. The maximum stress and deformation results of the cutoff wall are shown in Table 3. Because of the stress and deformation of the cutoff wall in different working conditions is similar, only the stress and deformation calculation results of the normal water level condition are listed, as shown in Figure 3 6. 
Table 3. The main displacement and stress calculation results of the concrete impervious wall

\begin{tabular}{|c|c|c|c|c|c|c|c|}
\hline \multirow{2}{*}{\multicolumn{2}{|c|}{ Maximum value }} & \multicolumn{3}{|c|}{ Without seepage-stress coupling } & \multicolumn{3}{|c|}{ With seepage-stress coupling } \\
\hline & & Normal & Design & Check & Normal & Design & Check \\
\hline Deformation & Vtion di & 10 & Inomal & Inowal & Inowal & Iaral & 10 - \\
\hline 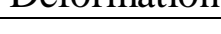 & vertical uis- & -15.10 & $-1 J .40$ & -15.70 & -15.20 & -19.50 & -17.00 \\
\hline $\mathrm{cm}$ & Horizontal & 7.60 & 4.39 & 4.71 & 10.40 & 4.88 & 5.41 \\
\hline Stress & Minor princip- & -1.84 & -2.27 & -2.35 & -2.05 & -2.67 & -2.75 \\
\hline $\mathrm{MPa}$ & Principal stress & 0.268 & 0.323 & 0.326 & 0.294 & 0.361 & 0.367 \\
\hline
\end{tabular}

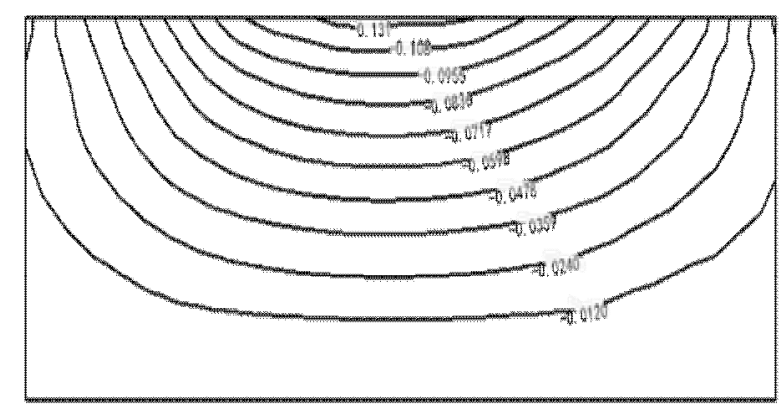

(a) Without seepage-stress coupling

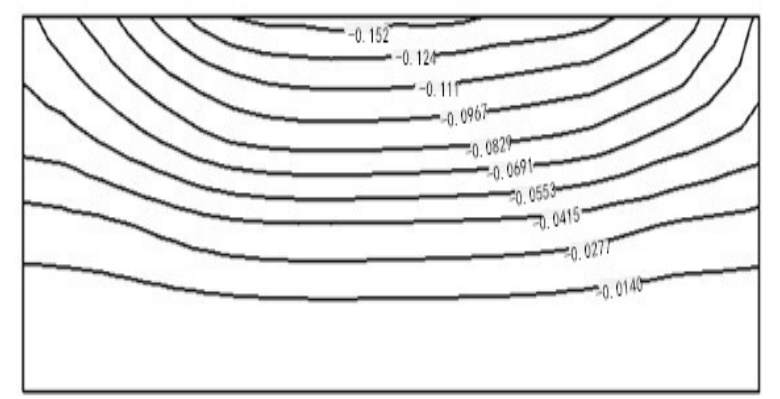

(b) With seepage-stress coupling

Figure 2. Vertical displacement contour map of impervious wall under normal water storage condition

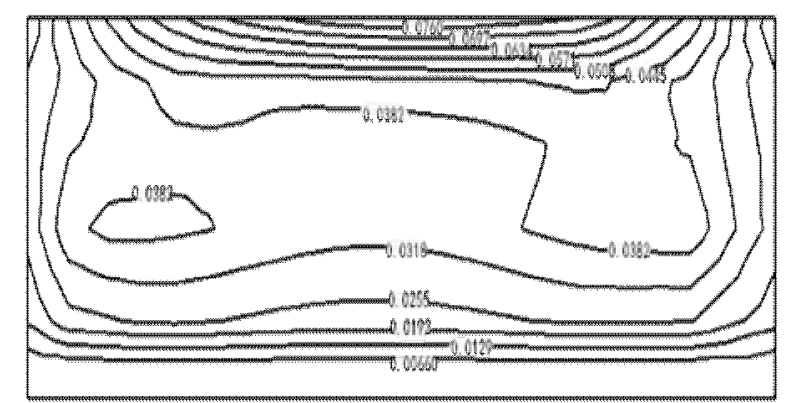

(a) Without seepage-stress coupling 


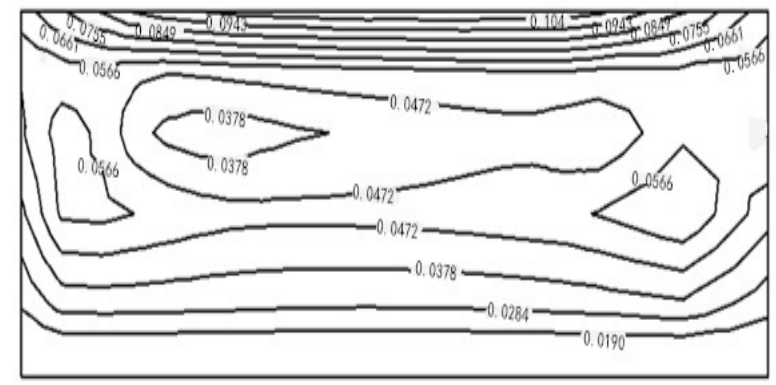

(b) With seepage-stress coupling

Figure 3. Horizontal displacement contour map of impervious wall under normal water storage condition

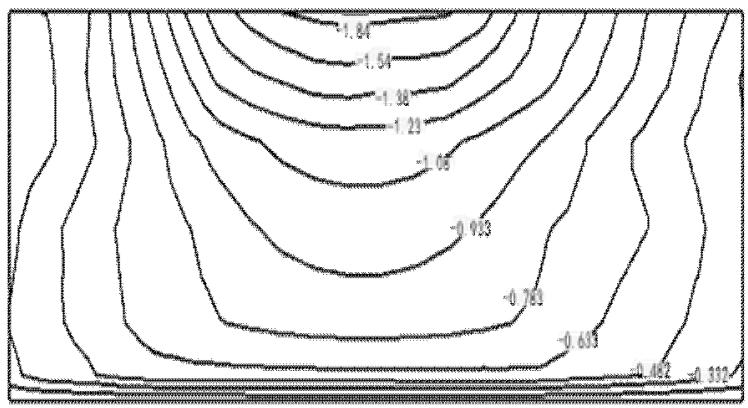

(a) Without seepage-stress coupling

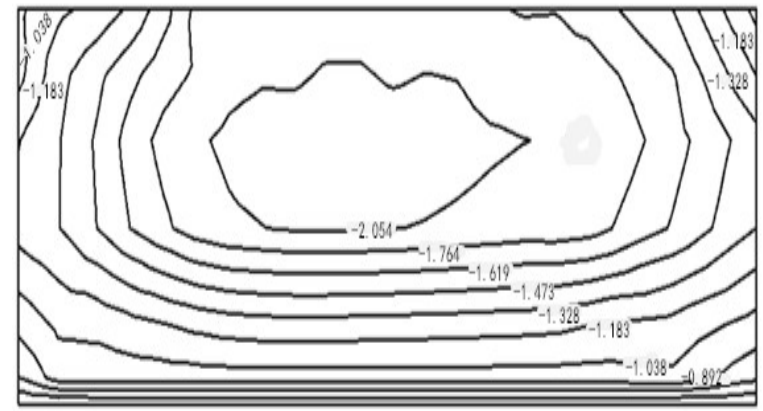

(b) With seepage-stress coupling

Figure 4. Small principal stress contour map of impervious wall under normal water storage condition

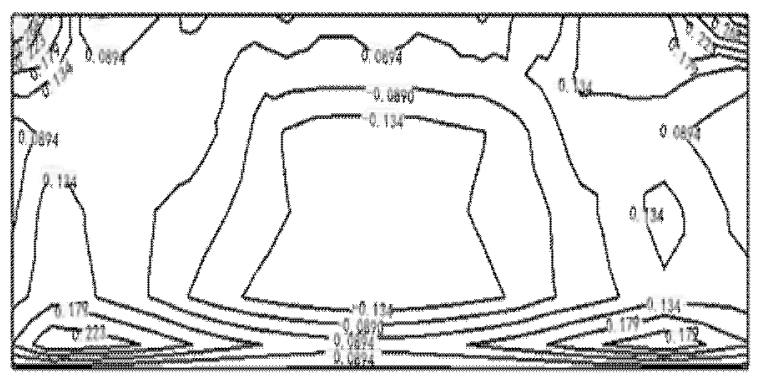

(a) Without seepage-stress coupling 


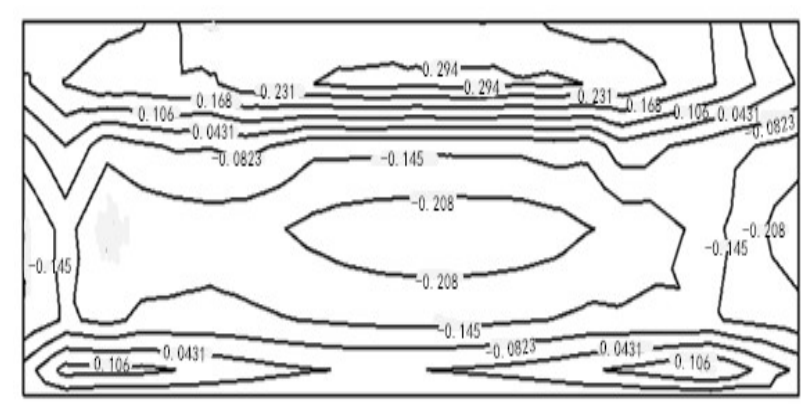

(b) With seepage-stress coupling

Figure 5. Principal stress contour map of impervious wall under normal water storage condition

Can be seen from Table 3 and Figure 3 6: under consideration and without consideration of the coupling effect of seepage and stress, the vertical displacement of the concrete cutoff wall is vertical and downward, and the horizontal displacement all point to the direction of the downstream, the maximum displacement occurs at the top of the cutoff wall, and gradually decreases with the increase of the depth; the maximum value of the minor principal stress (the compressive stress) of the cutoff wall occurs in the upper part of the cutoff wall, and gradually decreases with the surrounding; the principal stress (tensile stress) of the cutoff wall is compressive stress at the middle part of the wall, and the tensile stress at both ends of the upper and lower ends.

The maximum stress deformation of the cutoff wall is compared with the two cases that consideration and without consideration of the seepage-stress coupling. It can be seen that as the water level rises, the vertical displacement of the concrete cutoff wall continues to increase, while the horizontal displacement decreases and then increases, analysis of the possible reasons are: under the condition of nuclear flood water level, the downstream water level rises, the upper and lower surfaces of the gate piers all have the function of water loading, and the action of the water load is generated. With the increase of water level, the principal stress and the minor principal stress of concrete cutoff wall is increasing.

When considering the seepage-stress coupling, compared with the calculation results of without seepage-stress coupling, the vertical displacement and horizontal displacement of concrete cutoff wall have almost no change in the distribution law, and the displacement is increased; there are obvious differences in the distribution and size of the principal stress and the minor principal stress of the cutoff wall under consideration and without consideration of the coupling effect of seepage and stress, Specific performance as the position of the maximum value of the minor principal stress and the principal stress is moved down from the top of the cutoff wall to the upper part of the cutoff wall, and the minor principal stress is greatly increased. When the seepage-stress coupling is not considered, the calculation of the stress and deformation of the wall is obviously less than that of the actual situation.

\section{CONCLUSION}

In this paper, through the establishment of three-dimensional finite element model of a gate dam project, the stress and deformation characteristics of the concrete cutoff wall in deep overburden layer foundation are obtained by considering the seepage-stress coupling in two cases, we can draw the following conclusions: (1) The stress of the top of the cutoff wall is more concentrated, at the same time, the two ends of the wall up and down appear tensile stress, which may cause the cracks, need to be targeted to take preventive measures. (2) There are significant differences in the distribution and magnitude of the stress and deformation of the concrete cutoff wall under consideration and without consideration of the coupling effect of seepage and stress, and the stress and deformation of the wall is small when the seepage-stress coupling effect is neglected. Therefore, it is possible unsafe when simply ignore the coupling effect of seepage and stress, and it is necessary to consider the see- 
page-stress coupling effect in the study of the stress and deformation of the cutoff wall in the deep overburden layer.

\section{REFERENCES}

1)Lin, J.Y. 2009. Hydraulic structures. Beijing: China water\&power press.

2) Yang, Z.R. 2004. Analysis and Computation on 3D-Still Stress and Strain of Soil-Rock Dam in Xiaban Zone. Xi'an: Xi'an University of Technology.

3)Zhou, J.P. \& Chen, G.F. 2004. Anti seepage treatment of dam foundation and design of concrete cutoff wall in deep overburden foundation. Water Power 30(1): 299-306.

4) Yang, G.W. 2003. The Gate Dam Foundation Treatment Investigation of Deep and Thick Overburden. Sichuan: Sichuan university.

5)Zheng, H.S. et al. 2013. Optimization Algorithm of HBV Model Based on Linearized Parameter Calibration and Its Application. Water Resources and Power 31(9):76-78, 11.

6) Guo, X.M. et al. 2005. Stress Analysis on the Cutoff Wall of Plain Reservoirs. Journal of Zhejiang University of Water Resources and Electric Power 17(4): 10-14.

7) Liu, N. 2007. Three-Dimension Nonlinear Analysis of Earth-Rock Dam and the Stress Character Study of the Diaphragm Wall in Dams. Xi'an: Xi'an University of Technology.

8)Zhou, J.Y. 2013. Finite-element Analysis on Erath-rock Dam Reinforced by Concrete Cutoff Wall. Zhengzhou: Zhengzhou University.

9) Gao, J.L. 2012. Study on the interaction of cut-off wall and earth-rock dam based on coupling of seepage and stress. Tianjin: Tianjin University.

10) Chai, J.R. \& Li, S.Y. 2002. Analysis of Coupled Seepage and Stress Fields in Rock Mass Around the Daliushu Dam. Chinese Journal of Rock Mechanics and Engineering 21(Z2):23222325. 